\title{
Erratum to: Comparison of different rheological parameters for rutting susceptibility of SBS + WMA modified binders
}

\author{
Dharamveer Singh $^{1} \cdot$ Aniket V. Kataware ${ }^{1}$
}

Published online: 18 August 2016

(c) Springer International Publishing Switzerland 2016

Erratum to: Innov. Infrastruct. Solut. (2016)1:28

DOI 10.1007/s41062-016-0026-7

The original version of this article unfortunately contained a mistake in the abstract.

The expression (2) in the second sentence was incorrect. The correct expression is (2) Shenoy's parameter$G^{*} /(1-(1 / \tan \delta \sin \delta))$.

The original article was corrected.

The online version of the original article can be found under doi:10.1007/s41062-016-0026-7.

Dharamveer Singh

dvsingh@iitb.ac.in

Aniket V. Kataware

aniket.kataware@gmail.com

1 Department of Civil Engineering, Indian Institute

of Technology Bombay, Mumbai 400076, India 